\title{
DEPENDÊNCIA MICORRIZICA E PRODUÇÃO DE GLOMALINA POR FUNGOS MICORRIZICOS ARBUSCULARES INOCULADOS EM GRAVIOLEIRA ADUBADA COM COMPOSTO ORGÂNICO DA CASCA DE CACAU
}

\author{
Gedeon Almeida Gomes Júnior ${ }^{1,}$ Rafaela Alves Pereira², Eduardo Gross ${ }^{3}$ \\ 'MSc em Produção Vegetal, Universidade Estadual de Santa Cruz, Ilhéus-Ba \\ ${ }^{2}$ DSc em Produção Vegetal, Universidade Estadual de Santa Cruz, Ilhéus-Ba \\ 3Professor Pleno, Universidade Estadual de Santa Cruz, llhéus-Ba
}

Autor para correspondência: Gedeon Almeida Gomes Júnior, geda_almeida@hotmail.com

\begin{abstract}
RESUMO: O estudo objetivou avaliar o efeito da inoculação de fungos micorrízicos arbusculares (FMA-Acaulospora scrobiculata, Acaulospora colombiana e a mistura desses inóculos) e de doses do composto orgânico da casca de cacau $\left(0,5,10,20\right.$ e $\left.30 \mathrm{~g} \mathrm{dm}^{-3}\right)$ em mudas seminais de gravioleira tipo 'Morada'. 0 delineamento experimental foi 0 de blocos casualizados, com 4 blocos e em esquema fatorial $5 \times 4$ (FMA x Composto orgânico). Após 120 dias de crescimento observou-se que a gravioleira apresentou elevada dependência micorrizica em todos os níveis de adubação avaliados, sendo considerada uma espécie vegetal micotrófica obrigatória. Além disso, notou-se que a inoculação com os FMAs Acaulospora colombiana e Acaulospora scrobiculata elevaram os teores de glomalina facilmente extraível em agregados do solo.
\end{abstract}

PALAVRAS-CHAVE: Annona muricata L., proteína do solo, micorrizas, compostagem.

\section{MYCORRHIZAL DEPENDENCE AND GLOMALIN PRODUCTION BY MICROBRICAL FUNGI ARBUSCULAR INOCULATED IN SOURSOP FILLED WITH ORGANIC COMPOST OF COCOA SHELL}

\begin{abstract}
The objective of this study was to evaluate the effect of inoculation of arbuscular mycorrhizal fungi (AMF - Acaulospora scrobiculata, Acaulospora colombiana and the mixture of these inoculants) and organic cocoa pod doses $\left(0,5,10,20\right.$ and $\left.30 \mathrm{~g} \mathrm{dm}^{-3}\right)$ in seminal seedlings of 'Morada' soursop. The experimental design was a randomized block design with 4 blocks and a $5 \times 4$ factorial scheme (FMA x Organic Compound). After 120 days of growth it was observed that the soursop presented high mycorrhizal dependence at all fertilization levels evaluated, being considered a compulsory myotrophic plant species. In addition, it was noted that inoculation with the Acaulospora colombiana and Acaulospora scrobiculata AMF increased the levels of glomalin easily extractable in soil aggregates.
\end{abstract}

KEY WORDS: Annona muricata L., soil protein, mycorrhiza, composting.

\section{INTRODUÇÃO}

A gravioleira (Annona muricata L.) é considerada a segunda anonácea em produção em área cultivada no Brasil. Seu cultivo tem crescido bastante nos últimos anos, especialmente no sul da Bahia, pelas condições edafoclimáticas favoráveis e como alternativas rentáveis à lavoura cacaueira (Lemos, 2014). A crescente demanda por seus frutos para consumo in natura e, principalmente, para 0 setor da agroindústria, tem impulsionado a expansão da área cultivada, colocando a cultura como uma das principais alternativas de investimento do setor frutícola nordestino (Costa et al., 2005; Samarão et al., 2011).
De acordo com Silva et al.(2011) o uso de adubos compostados pode constituir uma alternativa interessante na formação de mudas de gravioleira. 0 sul da Bahia, devido à sua grande área plantada de cacaueiros, apresenta grande potencial em gerar resíduos, sendo a casca do fruto do cacaueiro 0 principal resíduo orgânico acumulado nas lavouras, que quando não adequadamente reaproveitado pode constituir fonte de inóculo para fungos patogênicos para a cultura do cacau (Mororó, 2012).

Os fungos micorrizicos arbusculares (FMA) são microorganismos do solo que estabelecem uma associação mutualista com a maioria de plantas vasculares, onde a planta fornece substrato energético 
através de fotoassimilados ao fungo, e este, utilizando seu micélio externo, capta nutrientes e água do solo e os transfere a planta hospedeira, proporcionando maior crescimento ao vegetal (Genre e Bonfante, 2010).

$A$ inoculação com fungos micorrizicos arbusculares (FMA) vem sendo estudada em algumas frutíferas (Farias et al., 2014: Riter Neto et al., 2014; Soares et al., 2012), inclusive em gravioleira (Samarão et al., 2011). No entanto, poucos estudos têm avaliado o grau de micotrofia da espécie aos FMA.

A glomalina é considerada uma proteína estável e abundante no solo (Rillig et al., 2003), encontrando-se estreitamente correlacionada com a estabilidade de agregados e com 0 carbono e 0 nitrogênio do solo (Nichols e Wright, 2005; Vilela et al., 2014). Especula-se que fatores do solo que influenciam os fungos micorrízicos arbusculares também interferem na produção de glomalina (Silva et al., 2012). Assim, o objetivo do trabalho foi avaliar o efeito do composto orgânico de casca de cacau e da inoculação de FMAs na dependência micorrizica da gravioleira e na produção de glomalina.

\section{MATERIAL E MÉTODOS}

0 estudo foi desenvolvido Universidade Estadual de Santa Cruz (UESC), em casa de vegetação, em que foi utilizado um delineamento estatístico em blocos casualizados, constando de 4 blocos, em um esquema fatorial $4 \times 5$, sendo 4 tratamentos micorrízicos: controle não inoculado, inoculação com Acaulospora scrobiculata, com Acaulospora colombiana e a mistura desses inóculos (MIX); e 5 doses do composto orgânico a base de casca de cacau ( $0 ; 5 ; 10 ; 20$ e $30 \mathrm{~g} \mathrm{dm}^{-3}$ ), totalizando 20 tratamentos com 1 repetição por bloco.

O composto orgânico foi produzido a partir da casca de frutos de cacau triturada e enriquecida com fosfato natural (fonte de P). As pilhas de compostagem foram dispostas em configuração geométrica cônica e o processo de compostagem foi o de reviramento ou "Window". As pilhas foram revolvidas a cada 15 dias nos primeiros 90 dias e a temperatura foi acompanhada quinzenalmente. Os inóculos de fungos micorrízicos arbusculares foram obtidos junto a Embrapa Agrobiologia, e foram adicionados a aproximadamente $3 \mathrm{~cm}$ de profundidade em uma densidade de 30 esporos por vaso.

A dependência micorrízica (DM) em cada dose do composto orgânico foi calculada seguindo metodologia proposta por Plenchette et al. (1983), baseando-se nos valores de biomassa seca das plantas micorrizadas. Utilizando-se das categorias descritas por Habte e Manjunath (1991), que classifica as plantas como excessivamente dependente (ED) (DM > 75\%), altamente dependente (AD) (DM entre 50 a 75\%), moderadamente dependente (MoD) (DM entre 25 e $50 \%)$, marginalmente dependentes $(\mathrm{MaD})(\mathrm{DM}<25 \%)$ ou independentes (In) (sem resposta a inoculação).

A extração da glomalina facilmente extraível (GFE) foi realizada conforme metodologia de Wright e Upadhyaya (1996) e quantificada pela técnica de microtitulação de Bradford (1976). Para quantificar a GFE foram utilizadas amostras de $2 \mathrm{~g}$ de agregados do solo, em seguida foi adicionado $8 \mathrm{~mL}$ do tampão citrato de sódio $20 \mathrm{mM}$ com pH 7. As amostras passaram por autoclavagem a $121^{\circ} \mathrm{C}$ por 30 minutos e em seguida foram centrifugadas a 10.000 RPM durante $5 \mathrm{~min}$. Ao final o sobrenadante foi pipetado e armazenado em tubos tipo Eppendorfs à $4{ }^{\circ} \mathrm{C}$ até o processo de microtitulação e leitura.

A microtitulação foi realizada em placas tipo ELISA com 96 poços, primeiramente foi estabelecida a curva padrão com a utilização de soro albumina bovina (BSA) como proteína purificada (PURIN, 2005), solução tampão citrato de sódio $20 \mathrm{mM}$ e reagente Bradford (Bradford, 1976). Em cada poço foram adicionados $5 \mu \mathrm{L}$ do extrato previamente extraído dos agregados, $45 \mu \mathrm{L}$ de agua destilada e $50 \mu \mathrm{L}$ do reagente de Bradford. As placas foram levadas a Espectrofotômetro Spectramax Paradigm (Molecular devices) para efetuar a leitura a uma diluição de 0,2 e uma absorbância de $595 \mathrm{~nm}$. Os resultados foram expressos em mg mL ${ }^{-1} \mathrm{e}$ posteriormente transformados em mg g-1 de solo.

\section{RESULTADOS E DISCUSSÃO}

Houve interação entre as doses do composto orgânico e os FMA inoculados em gravioleira para porcentagem de DM e teor de GFE no solo aos 120 dias após o plantio de mudas de gravioleira inoculada com FMA e adubadas com doses de composto orgânico $(p \leq 0,05)$. A DM da gravioleira as espécies de FMA inoculadas somente diferiu na dose mais elevada do composto orgânico, em que as plantas inoculadas com A. colombiana foram em média, menos dependentes da simbiose micorrizica, com A. scrobiculata e Mix, não diferindo entre si (Tabela 1). Destaca-se que os valores de DM foram elevados até mesmo na dose mais 
elevada da adubação com o composto orgânico. Nesse estudo, de acordo com a metodologia estabelecida por Habte e Manjunath (1991), a gravioleira quase sempre foi excessivamente dependente (ED) aos FMAs, sendo altamente dependente na dose mais elevada de adubação orgânica (Tabela 1).

Tabela 1. Dependência micorrizica e níveis categóricos das mudas de gravioleira submetidas diferentes doses de composto orgânico e inoculadas com A. colombiana, A. scrobiculata e a mistura desses dois fungos micorrízicos (MIX)

\begin{tabular}{|c|c|c|c|c|c|}
\hline \multirow{2}{*}{ Tratamento micorrízico } & \multicolumn{5}{|c|}{ Doses composto $\left(\mathrm{g} \mathrm{dm}^{-3}\right)$} \\
\hline & 0 & 5 & 10 & 20 & 30 \\
\hline Acaulospora scrobiculata & $84(E D) a$ & $84(E D) a$ & $84(E D) a$ & 78 (ED) a & $75(A D) a$ \\
\hline Acaulospora colombiana & 88 (ED) a & $88(E D) a$ & $86(E D) a$ & 77 (ED) a & $65(A D) b$ \\
\hline MIX & 85 (ED) a & 88 (ED) a & $88(E D) a$ & 79 (ED) a & $73(A D) a$ \\
\hline
\end{tabular}

Médias seguidas das mesmas letras nas colunas não diferem estatisticamente pelo teste de Tukey a $5 \%$ de probabilidade. ED: Excessivamente dependente; AD: Altamente dependente.

Resultados similares foram relatados por Brandão (2003), em que a gravioleira foi classificada como altamente dependente aos fungos micorrizicos arbusculares, mesmo nas doses mais elevadas de P. Os elevados valores de dependência micorrizica da gravioleira fazem com que essa planta possa ser considerada uma espécie micotrófica obrigatória, ou seja, é uma planta que depende da simbiose micorrízica independentemente do nível de fertilidade do solo que essa se encontra, principalmente em relação a nutrientes com mobilidade reduzida no solo. De acordo com Azcón-Aguilar et al. (1994) a Annona cherimoia, espécie do mesmo gênero da gravioleira, também é uma espécie micotrófica obrigatória.

$A$ adição de inoculos $A$. Colombiana, $A$. scrobiculata e a mistura dos dois ao solo elevou os teores de glomalina no solo, que foram estatisticamente superiores ao tratamento não inoculado independente da dose de composto orgânico aplicada. A aplicação isolada dos FMA apresentou incremento médio de $23,81 \%$ quando comparado ao tratamento não inoculado (controle). Quando a aplicação dos FMA ocorreu de forma conjunta com as doses de composto orgânico os incrementos de GFE foram superiores a $40 \%$ quando comparado ao controle (Tabela 2).

Tabela 2. Valores médios para a concentração de glomalina no solo após o plantio com mudas de gravioleira inoculadas com A. Colombiana, A. scrobiculata e a mistura desses dois fungos micorrízicos (Mix), e não inoculada (controle) e submetida a diferentes doses de composto orgânico

\begin{tabular}{cccccc}
\hline \multirow{2}{*}{ Tratamento micorrizico } & \multicolumn{5}{c}{ Doses composto $\left(\mathrm{g} \mathrm{dm}^{-3}\right)$} \\
\cline { 2 - 6 } & 0 & 5 & 10 & 20 & 30 \\
\hline Controle & $13,94 \mathrm{~b}$ & $14,50 \mathrm{~b}$ & $14,37 \mathrm{~b}$ & $14,53 \mathrm{~b}$ & $13,96 \mathrm{~b}$ \\
Acaulospora scrobiculata & $17,25 \mathrm{a}$ & $19,96 \mathrm{a}$ & $20,31 \mathrm{a}$ & $21,04 \mathrm{a}$ & $20,92 \mathrm{a}$ \\
Acaulospora colombiana & $17,27 \mathrm{a}$ & $20,92 \mathrm{a}$ & $20,39 \mathrm{a}$ & $20,36 \mathrm{a}$ & $20,45 \mathrm{a}$ \\
MIX & $17,26 \mathrm{a}$ & $20,21 \mathrm{a}$ & $20,34 \mathrm{a}$ & $20,71 \mathrm{a}$ & $21,22 \mathrm{a}$ \\
\hline
\end{tabular}

Médias seguidas das mesmas letras nas colunas não diferem estatisticamente pelo teste de Tukey a $5 \%$ de probabilidade.

O composto orgânico apresentou habilidade para estimular a produção de glomalina nas hifas do FMAs inoculados, em que os incrementos foram curvilineares com taxas quadráticas de resposta para A. scrobiculata, A. colombiana e Mix (Figura 1). Silva et al. (2008), avaliaram a influência da adubação com vermicomposto sobre a produção de glomalina pelos FMA Gigaspora albida e Acaulospora longula, observando incrementos superiores a 100\% em comparação ao solo não adubado. Wuest et al. (2005) também registraram aumento na produção de glomalina em solo adubado com esterco bovino. Esses aumentos apresentados em solos adubados com manejo orgânico refletem melhorias na qualidade do solo, dada a correlação existente entre glomalina e agregação de partículas (Rillig, 2004). 
Figura 1. Análise de regressão para a concentração de glomalina no solo após o plantio com mudas de gravioleira inoculadas com $A$. colombiana, $A$. scrobiculata e a mistura desses dois fungos micorrízicos (Mix), e não inoculada (controle) submetida a diferentes doses de composto orgânico.

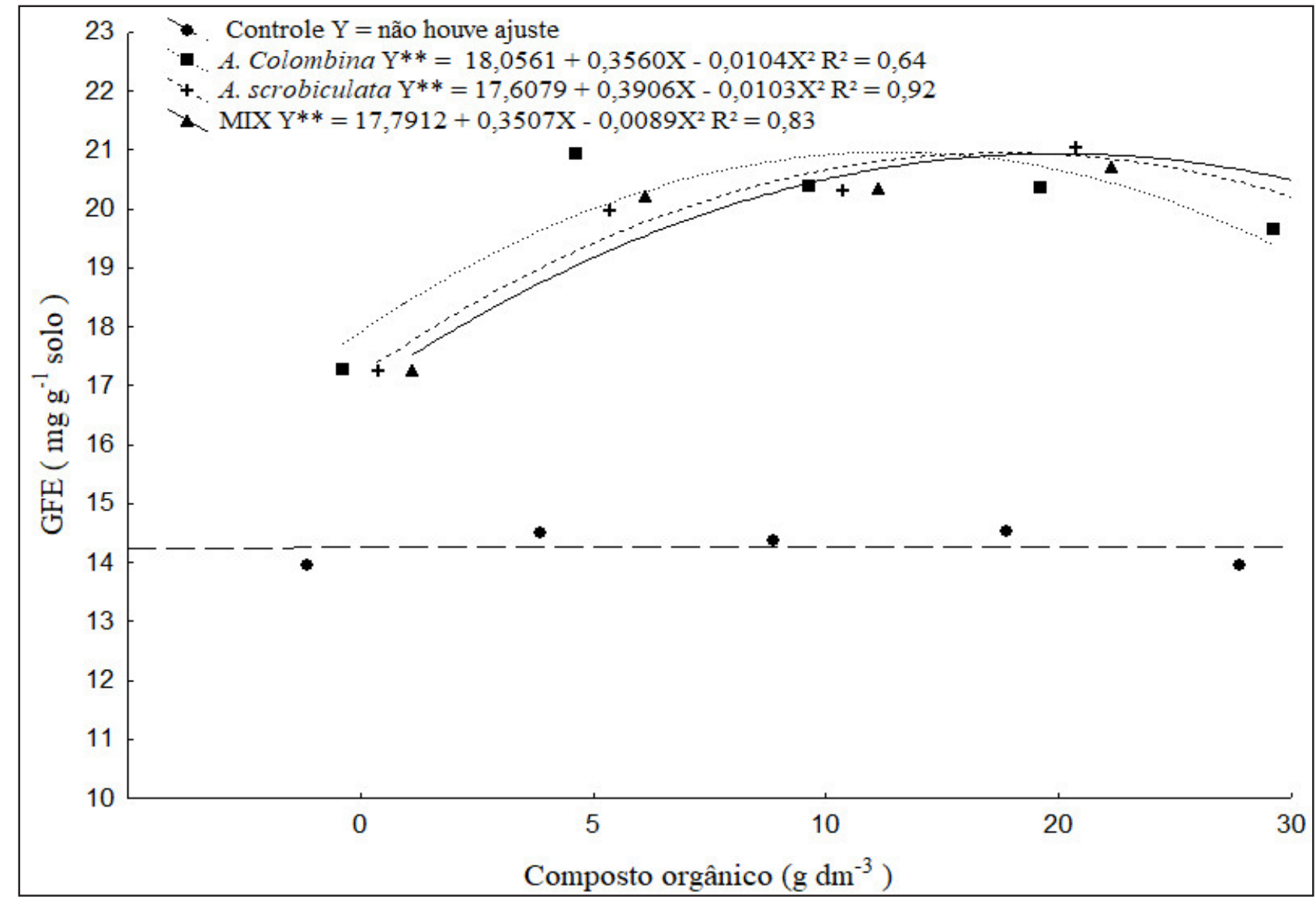

Nesse estudo, as curvas de respostaà aplicação de doses do composto orgânico apresentaram uma variação quadrática, evidenciando um efeito dose dependente na capacidade dos FMAs em produzir glomalina. Os resultados também indicaram que a gravioleira é uma espécie vegetal altamente dependentente da simbiose micorrizica.

Desta forma, o composto orgânico da casca de cacau elevou a produção de glomalina pelos FMA. E a gravioleira é uma altamente dependente a simbiose micorrizica.

\section{REFERÊNCIAS BIBLIOGRÁFICAS}

Azcón-Aguilar, C.; Encina, C.L.; Azcón, R.; Barea, J.M. Mycotrophy of Annona-cherimola and the morphology of its mycorrhizae. Mycorrhiza, 1994, 4, 161-168.

Bradford, M. M. A rapid and sensive method for the quantification of microgram quantities of protein utilizing the principle of protein-dye binding. Analytical Biochemistry, 1976, 72, 1-2, 248-254.
Brandão, J. A. C. Simbiose micorrízica arbuscular de gravioleiras (Annona Muricata) em solo infestado por pratylenchus coffeae. 74f. Dissertação, Universidade Federal de Pernambuco. Recife, 2003.

Costa, A. M. G.; Costa, J. T. A.; Cavalcanti-Júnior, A. T.; Correia, D.; Medeiros-Filho, S. Influência de diferentes combinações de substratos na formação de portaenxertos de gravioleira (Annona muricata L.). Revista de Ciência Agronômica, 2005, 36, 3, 299-305.

Farias, D. H.; Pinto, M. A. B.; Carra, B.; Schuch, M. W.; Souza, P. V. D. Desenvolvimento de mudas de mirtileiro inoculadas com fungos micorrízicos arbusculares. Revista Brasileira de Fruticultura, 2014, 36, 3, 655 663.

Genre A.; Bonfante P. The making of symbiotic cells in arbuscular mycorrhizal roots. In: Koltai H, Kapulnik Y. (eds.). Arbuscular mycorrhizas: physiology and function, $2^{\mathrm{a}}$ ed. Dordrecht Heidelberg, London, UK, New York, NY, USA: Springer, 2010. 57-71. 
Habte, M.; Manjunath, A. Categories of vesiculararbuscular mycoohizal dependency of host species. Mycorrhiza, 1991, 1, 3-12.

Lemos, E. E. P. de. A produção de anonáceas no Brasil. Revista Brasileira de Fruticultura, 2014, 36, 1, 77-85.

Mororó, R. C. Aproveitamento de derivados, subprodutos e resíduos do cacau. In: Valle, R. R. (ed). Ciência, tecnologia e manejo do cacaueiro, Ilhéus: CEPLAC/CEPEC, 2012. 597- 653.

Nichols, K. A.; Wright, S. F. Comparison of glomalin and humic acid in eight native US soils. Soil Science, 2005, 170, 985-997.

Rillig, M. C.; Ramsey, P. W.; Morris, S.; Paul, E. A. Glomalin, an arbuscular-mycorrhizal fungal soil protein, responds to land-use change. Plant and Soil, 2003, 253, 293-299.

Rillig, M.C. Arbuscular mycorrhizae, glomalin, and soil aggregation. Canadian Journal of Soil Science, 2004, 36, 355-399.

Riter-Netto, A. F.; Freitas, M. S. M.; Martins, M. A.; Carvalho, A. J. C.; Vitorazi-Filho, J. A. Efeito de fungos micorrízicos arbusculares na bioprodução de fenóis totais e no crescimento de Passiflora alata Curtis. Revista Brasileira de Plantas Medicinais, 2014, 16, 1 , 1-9.

Samarão, S. S.; Rodrigues, L. A.; Martins, M. A. Manhães, T. N.; Da Mota Alvim, L. A. Desempenho de mudas de gravioleira inoculadas com fungos micorrízicos arbusculares em solo não-esterilizado, com diferentes doses de fósforo. Acta Scientiarum Agronomy, 2011, 33, 1, 81-88.
Silva, D. K. A.; Silva, F. S. B.; Yano-Melo, A. M.; Maia, L.C. Uso de vermicomposto favorece o crescimento de mudas de gravioleira (Annona muricata L. 'Muricata') associada a fungos micorrizícos arbusculares. Acta Botanica Brasilica, 2008, 22, 3, 863-869.

Silva, E. B.; Farnezi, M. M. M. Limitações nutricionais para o crescimento de mudas de graviola em casa de vegetação em latossolo vermelho distrófico do norte de Minas Gerais. Bioscience Journal, 2011, 25, 6, 52-58.

Silva, C. F.; Simões-Araújo, J. L.; da Silva, E. M. R.; Pereira, M. G.; Freitas, M. S. M.; Júnior, O. J. S.; Martins, M. A. Fungos micorrízicos arbusculares e proteína do solo relacionada à glomalina em área degradada por extração de argila e revegetada com eucalipto e acácia. Ciência Florestal, 2012, 22, 4, 749-761.

Soares, A. C. F.; Sousa, C. S.; Garrido, M. S.; Lima, F. S. Fungos micorrízicos arbusculares no crescimento e nutrição de mudas de jenipapeiro. Revista Ciência Agronômica, 2012, 43, 1, 47-54.

Vilela, L.A.F., Saggin Júnior, O.J., Paulino, H.B., Siqueira, J.O., Santos, V.L. da S., Carneiro, M.A.C. Arbuscular mycorrhizal fungus in microbial activity and aggregation of a Cerrado Oxisol in crop sequence. Ciência e Agrotecnologia, 2014, 38, 34-42.

Wright, S. F.; Upadhyaya, A. Extraction of an abundant and unusual protein from soil and comparison with hyphal protein of arbuscular mycorrhizal fungi. Soil Science, 1996, 161, 9, 575-586.

Wuest, S.B.; Caesar-Tonthat, T.C.; Wrigth, S.F.; Williams, J.D. Organic matter addition, $\mathrm{N}$, and residue burning effects on infiltration biological and physical properties of intensively tilled silt-loam soil. Soil and Tillage Research, 2005, 84, 154-167. 